\title{
The Role of Chromium in the Hot Corrosion of Metals
}

\author{
Robert A. Rapp ${ }^{\mathrm{a}}$ and Nobuo Otsuka ${ }^{\mathrm{b}}$ \\ ${ }^{a}$ Mat. Sci. \& Eng. Dep't, The Ohio State University, Columbus, OH 43210 USA \\ ${ }^{b}$ Pipe \& Tube Dep't, Sumitomo Metal Industries, Amagasaki, Hyogo, 660-0891 Japan
}

The accelerated oxidation of metals and alloys by a thin surface film of fused salt is controlled by the local salt (acid-base) chemistry and oxidizing potential at the salt/scale interface, as can be monitored using ec surface probes. The solubility of chromium oxide in fused sodium sulfate as a function of melt chemistry at $1200 \mathrm{~K}$ is accurately known, with chromate ions as the dominant solute at high oxygen activities, but chromite ions dominate at low oxygen activities. Since the chromia solubility increases with increasing oxygen activity, solid chromia is not expected to precipitate out in the salt film during hot corrosion. Serving as a strong acid solute, the formation of chromite or chromate anions can serve as a buffer for the melt chemistry at the scale/salt interface. Chromite ions would be formed using the oxide ions released by less acidic oxides, e.g. $\mathrm{CoO}, \mathrm{NiO}$, $\mathrm{FeO}$, etc., thereby preventing the shift toward high local basicity, sulfide formation, and oxide dissolution/reprecipitation. Furthermore, chromate ions can precipitate back onto reducing sites (scale grain boundaries and flaws) on the alloy surface to block its contact with the salt.

\section{Introduction}

The hot corrosion of metals is a phenomenon of accelerated oxidation generally associated with the attack of hot components in a gas turbine engine. In that case, the dominant component of the thin fused salt deposit is usually based on sodium sulfate, a salt of high thermodynamic stability at high temperatures. This fused salt film is created by the reaction of sulfur impurity from the fuel with sodium from a sea salt origin or else some other source. The fused salt deposit can be formed either by a condensation process or else by physical deposition, e.g. the shedding of salt from an upstream filter. However, the hot corrosion phenomenon is quite general, pertaining also to other fused salt films in many other engineering systems (1). The bulk of fundamental studies in the literature are concerned with the high-temperature corrosion of Ni-base and Co-base alloys at temperatures near and above the melting point (886C) of pure sodium sulfate. This temperature regime, which will receive the emphasis of consideration in this paper, is called High-Temperature Hot Corrosion (HTHC) or Type 1 (2).

From an engineering standpoint, chromium is known to be the most effective alloying element in combating hot corrosion, even when a protective chromia scale is not formed $(3,4)$. The authors will review the relevant literature, and offer a novel interpretation for the role of chromium in the hot corrosion of alloys by fused sodium sulfate. 


\section{Literature}

Studies of the melt chemistry (acid-base) of fused $\mathrm{Na}_{2} \mathrm{SO}_{4}$ and the solubilities of oxides in this fused salt have been facilitated immeasurably by the use of two electrochemical probes to measure the thermodynamic activities of oxygen and sodium, thereby providing a quantitative measure for melt basicity, defined as $\log \mathrm{a}_{\mathrm{Na} 2 \mathrm{O}}$ (5). These electrochemical probes have been used to measure the local melt basicity either at an independent working electrode in a deep melt, or else at the surface of a metal coupon experiencing hot corrosion beneath a thin salt film $(6,7)$.

\section{$\underline{\text { Solubility Studies }}$}

Zhang used two ec probes in the determination of the solubility of $\mathrm{Cr}_{2} \mathrm{O}_{3}$ in fused $\mathrm{Na}_{2} \mathrm{SO}_{4}$ at $1200 \mathrm{~K}$ for $\mathrm{P}_{\mathrm{O} 2}=1$ atm, as presented in Figure 1 (8). As clearly seen, the individual acidic and basic solutes obey exactly the predicted dependencies for their solubilities on basicity.

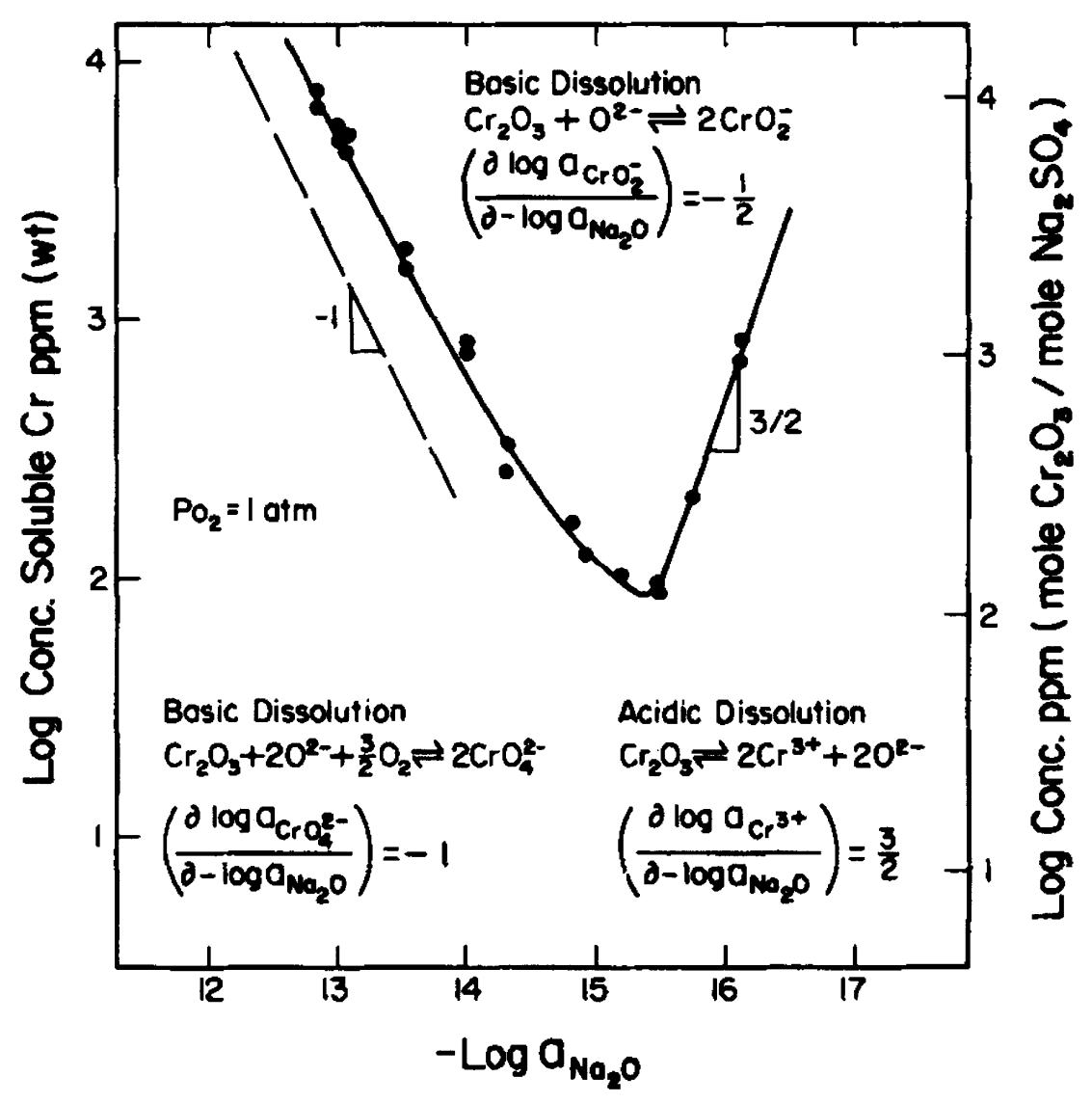

Figure 1. Solubility of $\mathrm{Cr}_{2} \mathrm{O}_{3}$ in fused $\mathrm{Na}_{2} \mathrm{SO}_{4}$ at $1200 \mathrm{~K}$ and $\mathrm{P}_{\mathrm{O} 2}=1 \mathrm{~atm}(8)$

At $1200 \mathrm{~K}$, the solubility minimum for $\mathrm{Cr}_{2} \mathrm{O}_{3}$ (about 100 wt. ppm $\mathrm{Cr}$ ) occurs at a melt basicity which nominally corresponds to that for equilibrium between $\mathrm{Na}_{2} \mathrm{SO}_{4}$ and a typical combustion product gas for a gas turbine $\left(\mathrm{P}_{\mathrm{SO} 3}=10^{-3} \mathrm{~atm}\right)$. Therefore, the 
formation of the acidic solute would hardly be expected in practice. A most important characteristic of the basic chromate solute is its dependence on oxygen activity $\left[\mathrm{Na}_{2} \mathrm{CrO}_{4}\right]_{\mathrm{sol}}=\mathrm{KP}_{\mathrm{O} 2}{ }^{3 / 4}$, which is proposed to be a key factor in the role of $\mathrm{Cr}$ in the abatement of hot corrosion.

$$
\begin{aligned}
& \mathrm{Cr}_{2} \mathrm{O}_{3}+2 \mathrm{Na}_{2} \mathrm{O}+3 / 2 \mathrm{O}_{2}=2 \mathrm{Na}_{2} \mathrm{CrO}_{4} \\
& \mathrm{~d} \log \left[\mathrm{Na}_{2} \mathrm{CrO}_{4}\right]_{\mathrm{sol}} / \mathrm{d} \log \mathrm{P}_{\mathrm{O} 2}=3 / 4
\end{aligned}
$$

In Fig.1, while the presence of the chromite $\left(\mathrm{NaCrO}_{2}\right)$ solute does appear near the solubility minimum for $\mathrm{P}_{\mathrm{O} 2}=1 \mathrm{~atm}$, this solute becomes the dominant basic solute under highly reducing conditions, e.g., as expected near the salt/scale interface.

Solubility measurements at a much lower oxygen activity $\left(\mathrm{P}_{\mathrm{O} 2}=10^{-11.5}\right.$ atm) indicated $\mathrm{NaCrO}_{2}$ (chromite), but not $\mathrm{Na}_{2} \mathrm{CrO}_{4}$ (chromate), as the dominant basic solute, as seen in Figure 2 (8). The dominant acidic solute for $\mathrm{P}_{\mathrm{O} 2}=10^{-11.5}$ atm is $\mathrm{CrS}$, and the global solubility minimum is displaced about three orders of magnitude to higher melt basicity compared to $\mathrm{P}_{\mathrm{O} 2}=1$ atm.

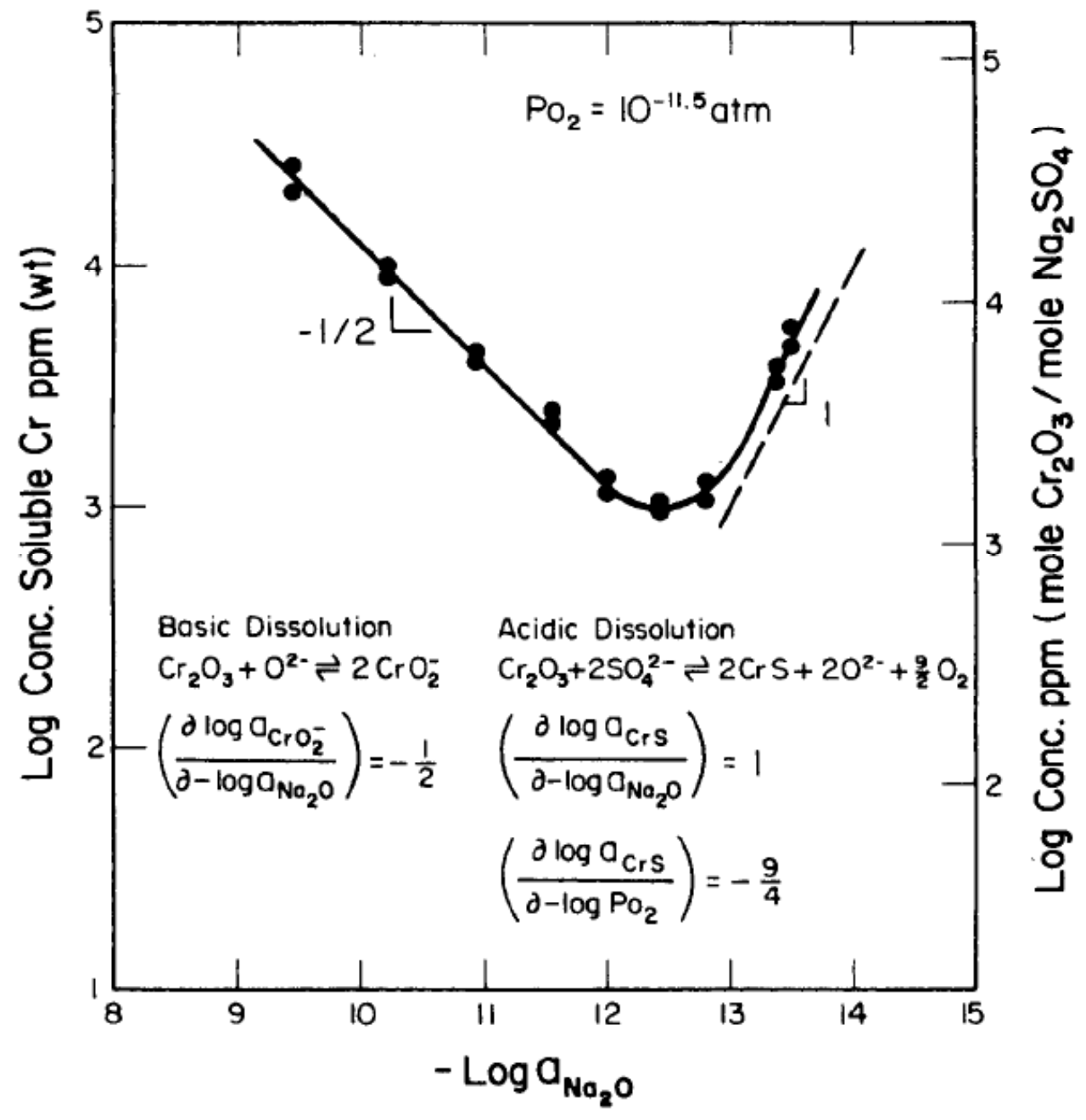

Figure 2. Solubility of $\mathrm{Cr}_{2} \mathrm{O}_{3}$ in fused $\mathrm{Na}_{2} \mathrm{SO}_{4}$ at $1200 \mathrm{~K}$ and $\mathrm{P}_{\mathrm{O} 2}=10^{-11.5}$ atm (8). 
Figure 3 shows a compilation of the results for the $\mathrm{Cr}_{2} \mathrm{O}_{3}$ solubility studies by Zhang (8). The solubility minimum for $\mathrm{P}_{\mathrm{O} 2}=1 \mathrm{~atm}$ at approximately $100 \mathrm{ppm}$ soluble $\mathrm{Cr}$, while not very low, is raised by an order of magnitude, or more, in a quite reduced salt, and the dominant solute in the reduced salt (near the salt/oxide interface) is $\mathrm{NaCrO}_{2}$. This solubility behavior is crucial to the role of $\mathrm{Cr}$ as an advantageous alloying element.

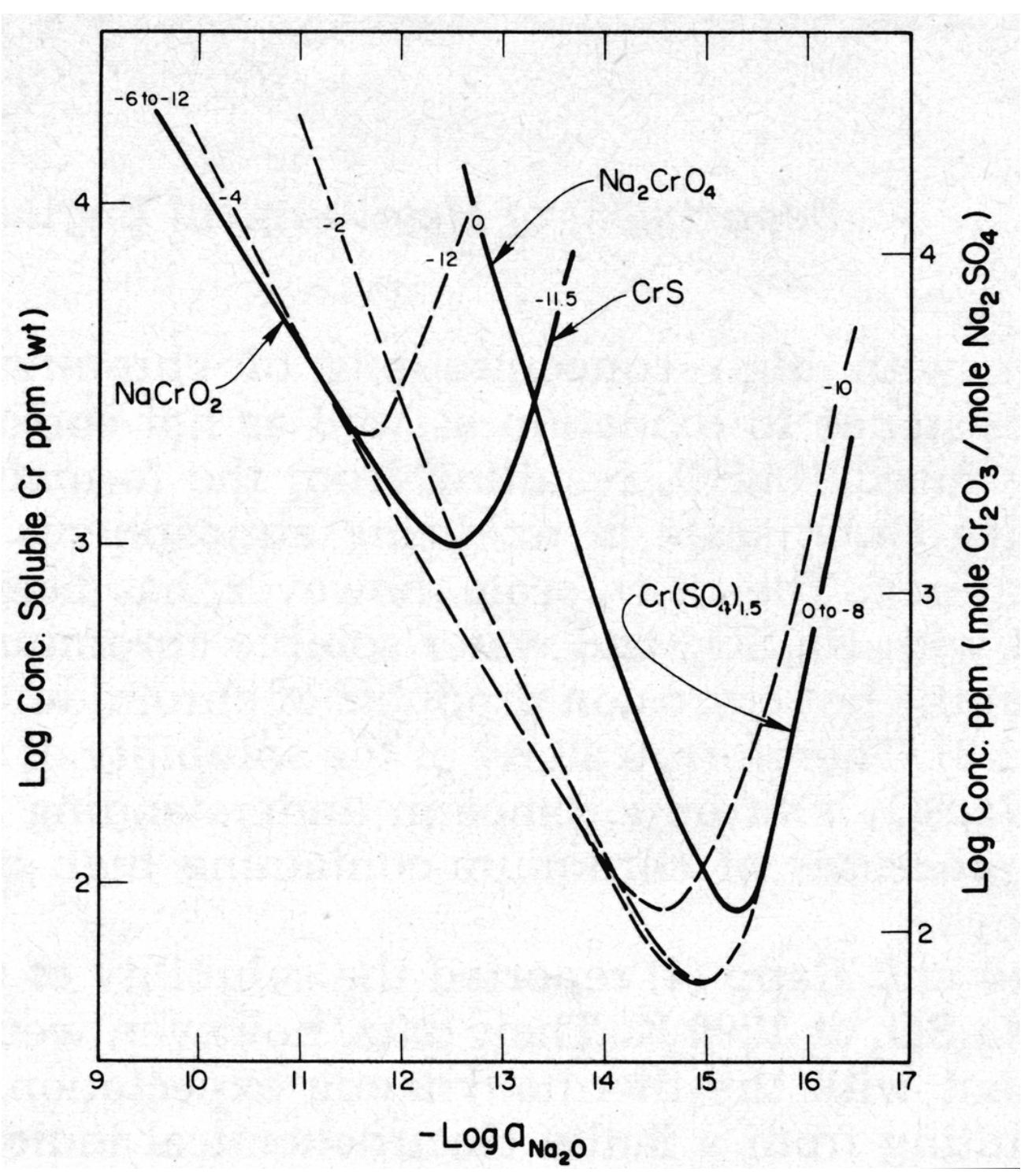

Figure 3. Measured and calculated solubilities of $\mathrm{Cr}_{2} \mathrm{O}_{3}$ in fused $\mathrm{Na}_{2} \mathrm{SO}_{4}$ at $1200 \mathrm{~K}$ for several oxygen pressures (8). ( $\log \mathrm{P}_{\mathrm{O} 2}$ indicated for each solubility curve)

The dependence of the $\mathrm{Cr}_{2} \mathrm{O}_{3}$ solubility on oxygen activity is further illustrated in Figure 4, from Zhang (8). The plot shows that for all melt basicities of interest, the $\mathrm{NaCrO}_{2}$ species is more soluble at low $\mathrm{P}_{\mathrm{O} 2}$, while $\mathrm{Na}_{2} \mathrm{CrO}_{4}$ is more soluble at higher $\mathrm{P}_{\mathrm{O} 2}$. Furthermore, the solubility of $\mathrm{Cr}_{2} \mathrm{O}_{3}$ is always greater at the more oxidizing gas/salt interface than at the more reduced scale/salt interface. 
Figure 5 presents a compilation of solubility plots for important oxides at $1200 \mathrm{~K}$, albeit for $\mathrm{P}_{\mathrm{O} 2}=1$ atm (5). This plot shows that $\mathrm{Cr}_{2} \mathrm{O}_{3}$, along with $\mathrm{Al}_{2} \mathrm{O}_{3}$, is the most acidic oxide in this collection and that many orders of magnitude in basicity separate the minima for the various oxides. The solutes of alumina, however, are limited to trivalent aluminum, so the solubility of $\mathrm{Al}_{2} \mathrm{O}_{3}$, unlike $\mathrm{Cr}_{2} \mathrm{O}_{3}$, is independent of oxygen activity. Engineering alloys for high-temperature service usually combine base metals of $\mathrm{Ni}, \mathrm{Fe}$, or Co (all forming rather basic oxides) with the more reactive components of $\mathrm{Cr}$ and $\mathrm{Al}$

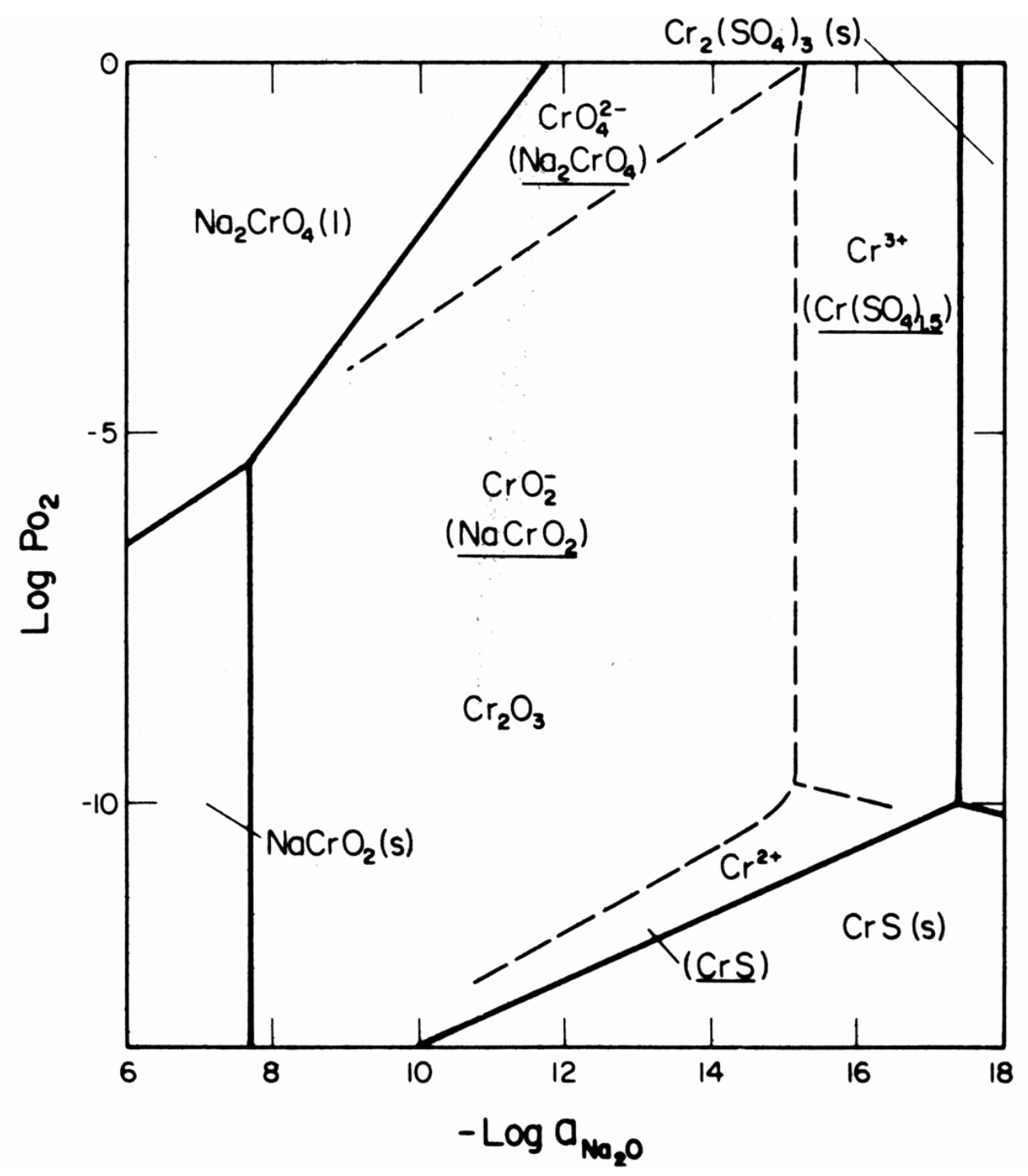

Figure 4. Dominant chromium solute species in $\mathrm{Na}_{2} \mathrm{SO}_{4}-\mathrm{Cr}_{2} \mathrm{O}_{3}$ system at $1200 \mathrm{~K}$ (8)

(each forming very acidic oxides). Then within a salt film coating on an alloy surface in an oxidizing environment, the conditions exist for interactions of the solutes for each oxide with those of another, in particular in the presence of gradients in both basicity and oxygen activity across the salt film. Such solute interactions were demonstrated by Hwang and Rapp in determining the individual rates of dissolution for powders of $\mathrm{Fe}_{2} \mathrm{O}_{3}$ and $\mathrm{Cr}_{2} \mathrm{O}_{3}$ in fused $\mathrm{Na}_{2} \mathrm{SO}_{4}$ at a basicity between the two solubility minima for these 
oxides in Fig. 5 (9). The individual dissolution rates for each oxide were then compared with those measured for each oxide in the mutual presence of the other oxide. The mutual presence of the two oxides was found to greatly increase the dissolution rates of each oxide, a phenomenon denoted as "synergistic dissolution" and described by the global reaction:

$$
2 \mathrm{Fe}_{2} \mathrm{O}_{3}+3 \mathrm{Cr}_{2} \mathrm{O}_{3}+9 / 2 \mathrm{O}_{2}=4 \mathrm{Fe}^{3+}+6 \mathrm{CrO}_{4}^{2-}
$$

Then during the oxidation of an Fe-Cr alloy coated by a film of fused $\mathrm{Na}_{2} \mathrm{SO}_{4}$, or likewise for $\mathrm{Ni}-\mathrm{Cr}$ or $\mathrm{Co}-\mathrm{Cr}$ alloys, the tendency to form an acidic solute by the oxides of $\mathrm{Fe}, \mathrm{Ni}$ or $\mathrm{Co}$ (with the release of oxide ions) is balanced by the tendency by $\mathrm{Cr}_{2} \mathrm{O}_{3}$ to react with those oxide ions to form chromite or chromate ions. In this way, the salt basicity at the salt/scale interface would be prevented from a shift to a more basic condition, and the chromium component acts as a buffer to stabilize the salt chemistry.

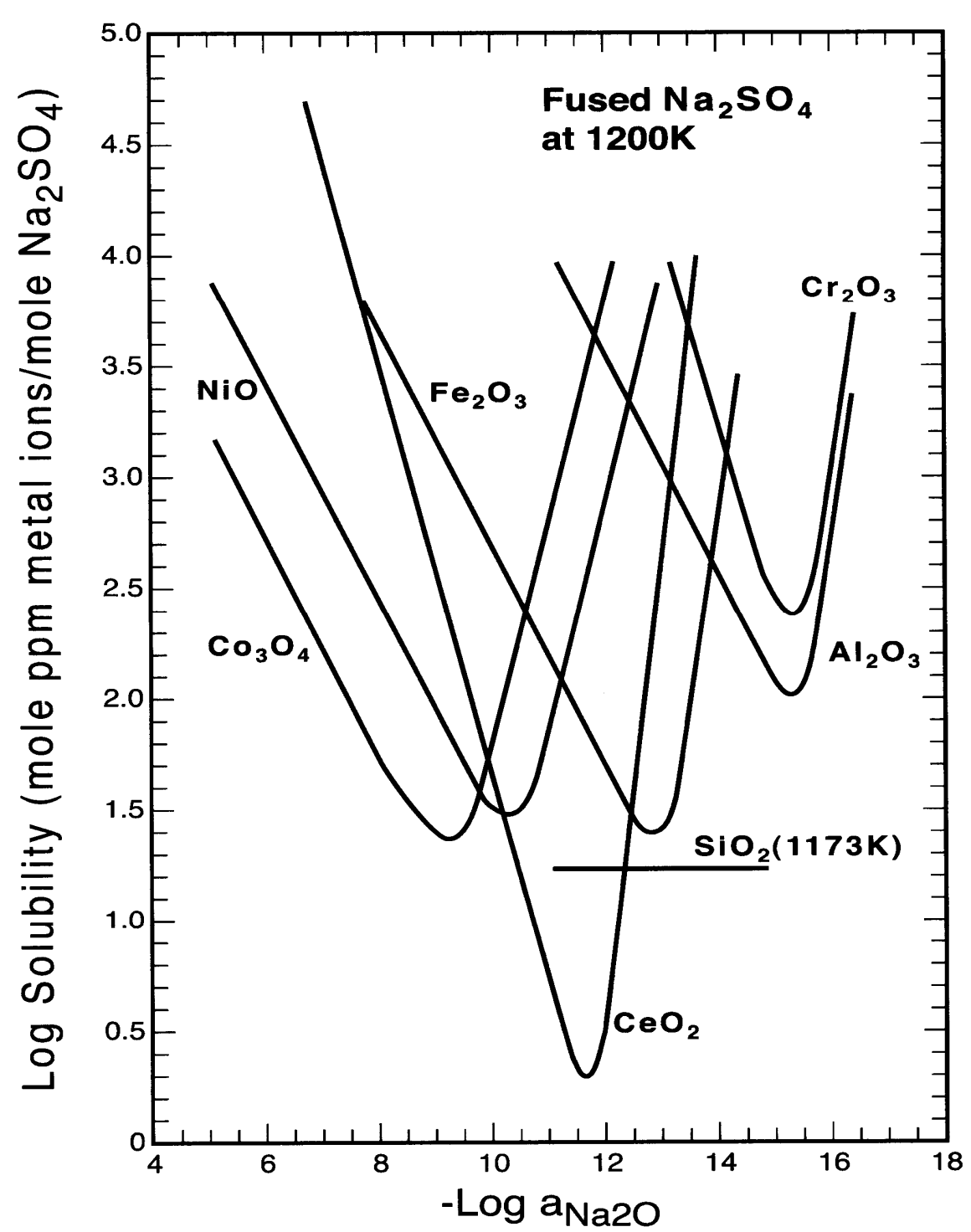

Figure 5. Measured oxide solubilities in fused $\mathrm{Na}_{2} \mathrm{SO}_{4}$ at $1200 \mathrm{~K}$ and $1 \mathrm{~atm} \mathrm{O}_{2}(5)$ 


\section{Type 1 Hot Corrosion Mechanism: Sulfidation-Basic Fluxing}

To rationalize and appreciate the role of $\mathrm{Cr}$ in minimizing hot corrosion, one must first consider the mechanism for continuing/unabated hot corrosion. In examining the microstructure of alloys corroded in the HTHC regime, sulfides are generally found in the metal, the reactive protective element $\mathrm{Cr}$ is depleted from the alloy, and the salt film contains particles (precipitates) of oxide which provide no protection. Goebel and Pettit proposed, for the hot corrosion of pure $\mathrm{Ni}$ in air, that the corrosion reaction was

$$
4 \mathrm{Ni}+\mathrm{Na}_{2} \mathrm{SO}_{4}=\mathrm{NiS}+\mathrm{Na}_{2} \mathrm{O}+3 \mathrm{NiO}
$$

whereby the combined oxidation and sulfidation of $\mathrm{Ni}$ necessarily increased the basicity of the salt film locally (11). Without the advantage of any solubility data for $\mathrm{NiO}$ in $\mathrm{Na}_{2} \mathrm{SO}_{4}$, they supposed that a basic solute $\mathrm{NaNiO}_{2}$ formed at the salt/oxide interface could be reprecipitated to form non-protective oxide particles farther out in the salt film (11). This "scale fluxing" model was quantified by Rapp and Goto who proposed the "negative solubility criterion" for sustained hot corrosion, namely:

$$
(\mathrm{d} \text { [oxide solubility] / } \mathrm{dx})_{\mathrm{x}=0}<0
$$

whereby a reduction in the solubility of the oxide (as any solute) in the direction of the salt/gas interface would result in the precipitation of oxide particles in the salt film, as illustrated in Fig. 6 (12).

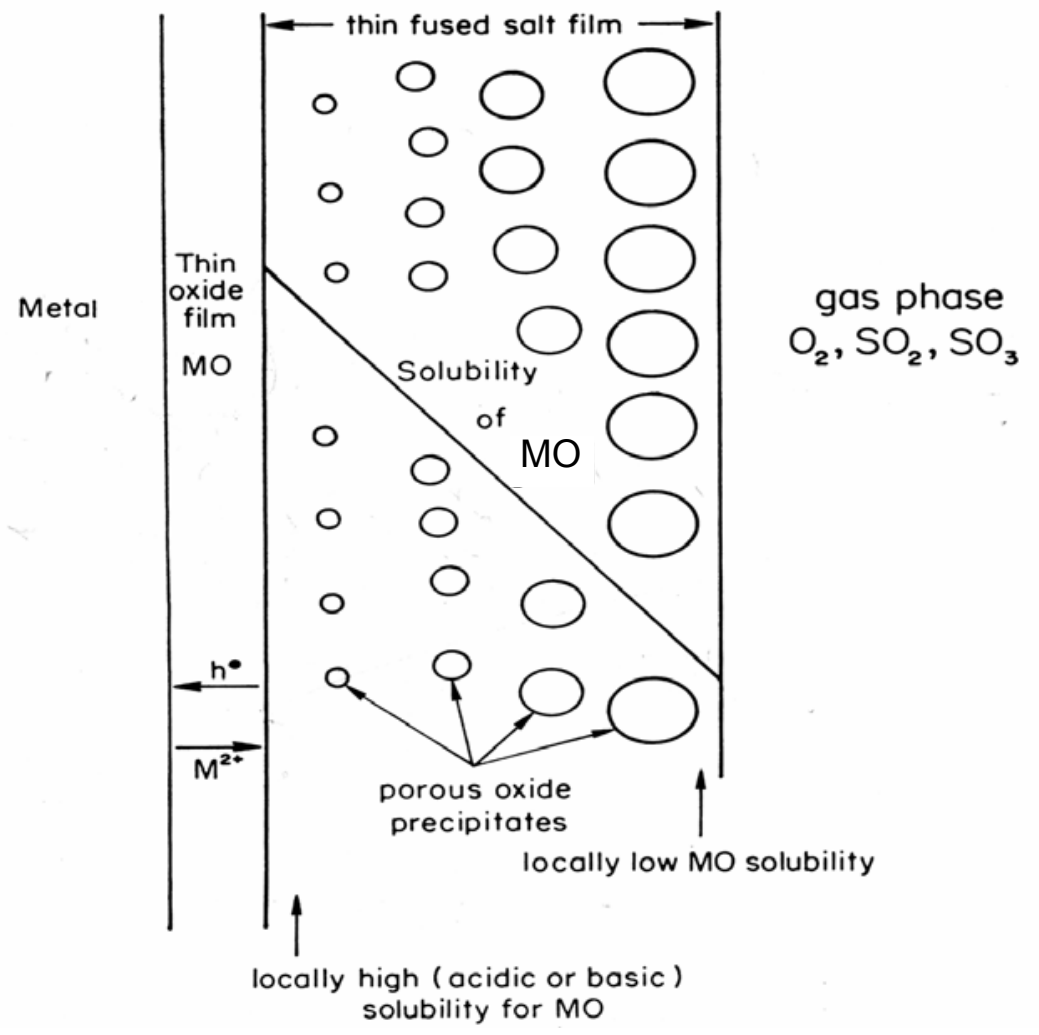

Figure 6. Reprecipitation of non-protective MO oxide particles supported by a negative solubility gradient in a thin salt film (12). 
Because the oxidizing potential for a thin salt film is obviously higher at the gas/salt interface, and the local melt basicity would be lower (contacting an acid gas), than at the salt oxide interface, the chromia solubility (see Figs. 3 and 4) clearly increases with distance from the oxide/salt interface. In other words, unlike most other oxides, chromia presents a positive solubility gradient in the salt film, and is not subject to the Rapp-Goto "negative solubility gradient" criterion for sustained hot corrosion caused by dissolution of the oxide at the oxide/salt interface with reprecipitation of particulate oxide in the salt film, as illustrated in Figure 6.

Figure 7 illustrates several sets of conditions which do satisfy the "negative solubility gradient" condition for sustained HTHC (12). If I represents the oxide/salt interface and II is the salt/gas interface in Figure 7, then a negative solubility gradient is satisfied for case A (basic fluxing) and for Case $\mathrm{C}$ (acidic fluxing), or if the local chemistries should straddle the solubility minimum for Case B. In some cases, of course, the effect of the local oxygen activities also enters into consideration.

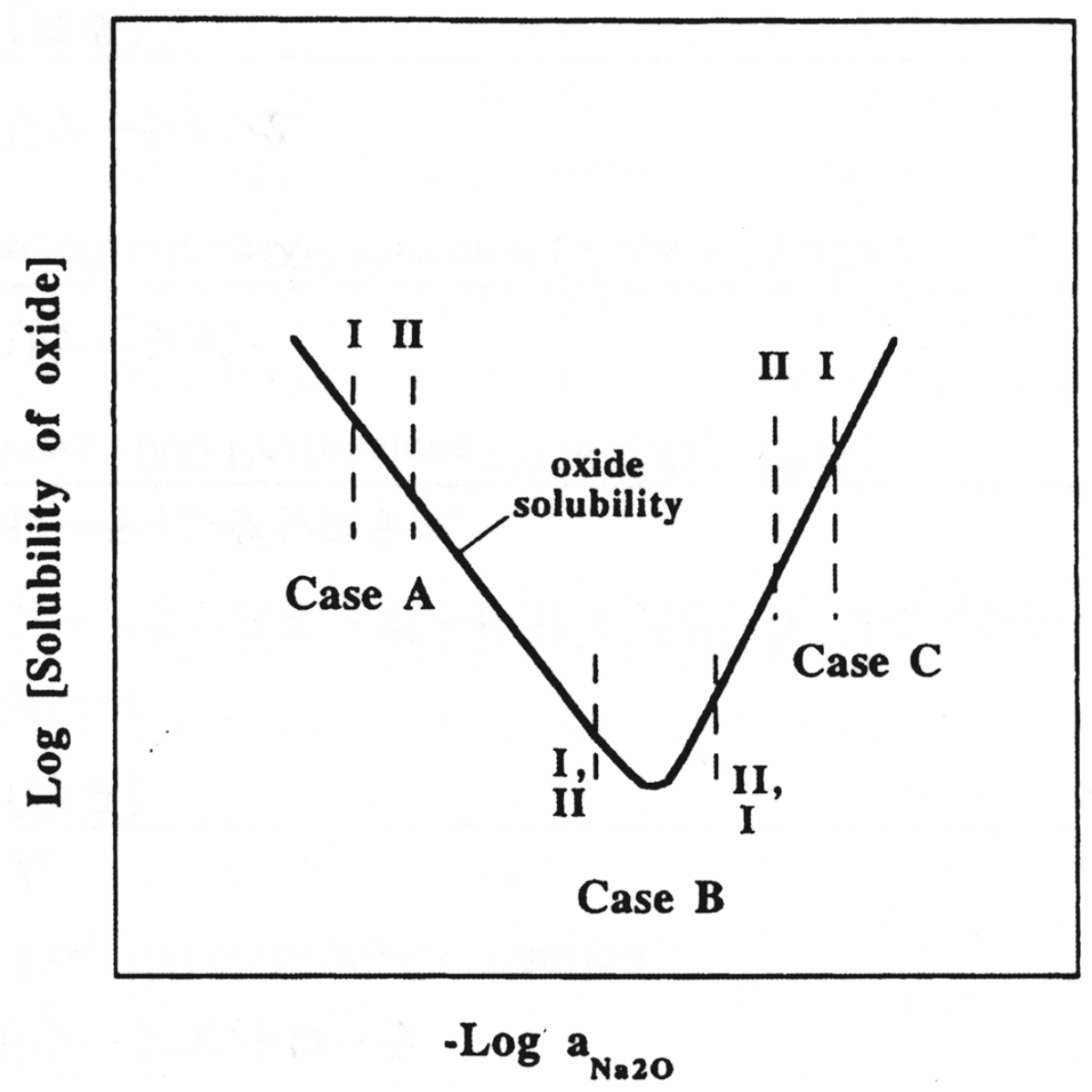

Figure 7. Cases of sustained hot corrosion of a pure metal (I is oxide/salt interface and II is the salt/gas interface) (12). 


\section{Electrochemical Studies}

A substantiation of the "basic fluxing" mechanism presented as Eq. [4] was provided by two electrochemical studies. Upon the deep cathodic polarization of a $\mathrm{Pt}$ electrode immersed in fused $\mathrm{Na}_{2} \mathrm{SO}_{4}$ at $900^{\circ} \mathrm{C}$, as illustrated in Figure 8, and as tracked by a pair of ec probes, the salt at the Pt/salt interface became sharply reduced, entering a regime of sulfide ion stability, whereby a simultaneous increase in local melt basicity (over several decades) occurred (13). This observation showed that the contact of a reactive base metal $(\mathrm{Ni}, \mathrm{Fe}, \mathrm{Cr}$, etc.) with the fused salt would also correspond to a deep cathodic reduction of the salt, leading to sulfidation and a dramatically increased melt basicity. Then if the oxide solubility should satisfy the "negative solubility criterion" for basic fluxing of Eq. [5], unabated hot corrosion could be expected.

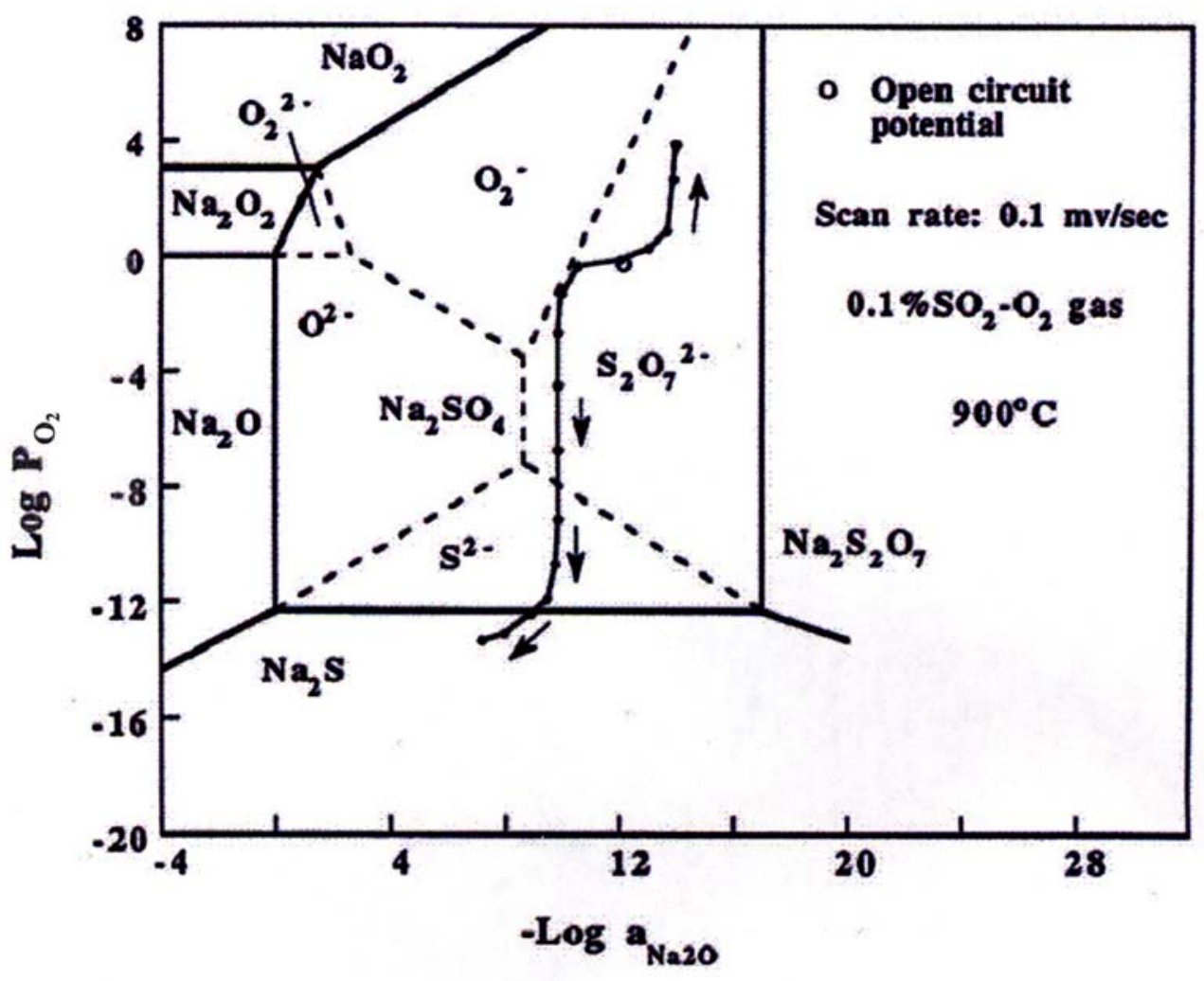

Figure 8. Trace of basicity and oxygen activity measured for porous Pt working electrode (13).

The present authors attached two ec probes to a preoxidized Ni coupon, immersed the combination into fused $\mathrm{Na}_{2} \mathrm{SO}_{4}$, and upon withdrawal leaving a thin adherent salt film, followed the salt chemistry in contact with the coupon during hot corrosion, as illustrated in Figure 9 (7). From the very start of the hot corrosion process, the salt/scale interface was significantly more reduced and more basic than that corresponding to the gas phase 
of $0.1 \% \mathrm{SO}_{2}-\mathrm{O}_{2}$. After a period of about 15 minutes, the coupon experienced a sharp reduction in the interfacial oxygen activity (stabilizing nickel sulfide) and a corresponding sharp increase (over about 4 decades) in the local melt basicity. The dashed line on Figure 9 corresponds to the locus for the minimum in NiO solubility (as a function of $\mathrm{P}_{\mathrm{O} 2}$ ). The increase in basicity (after 20 minutes) brought the interface into the field of basic dissolution for $\mathrm{NiO}$, where that oxide happens to satisfy the "negative solubility criterion" (Case A of Fig. 7). The result was that the coupon suffered severe sulfidation, and rapid extensive hot corrosion (NiO dissolution and reprecipitation in the salt film) until its total consumption after 11 hours. Many similar experiments with variations on the experimental variables showed that such hot corrosion was prevented whenever the interfacial chemistry was maintained to the right of (below) the $\mathrm{NiO}$ solubility locus line, because acidic hot corrosion of $\mathrm{Ni}$ (with a more acidic gas/salt interface) does not satisfy the "negative solubility gradient" criterion. This study suggests that the means to prevent hot corrosion is to buffer the local interfacial salt chemistry such that the dissolution/reprecipitation criterion is not satisfied.

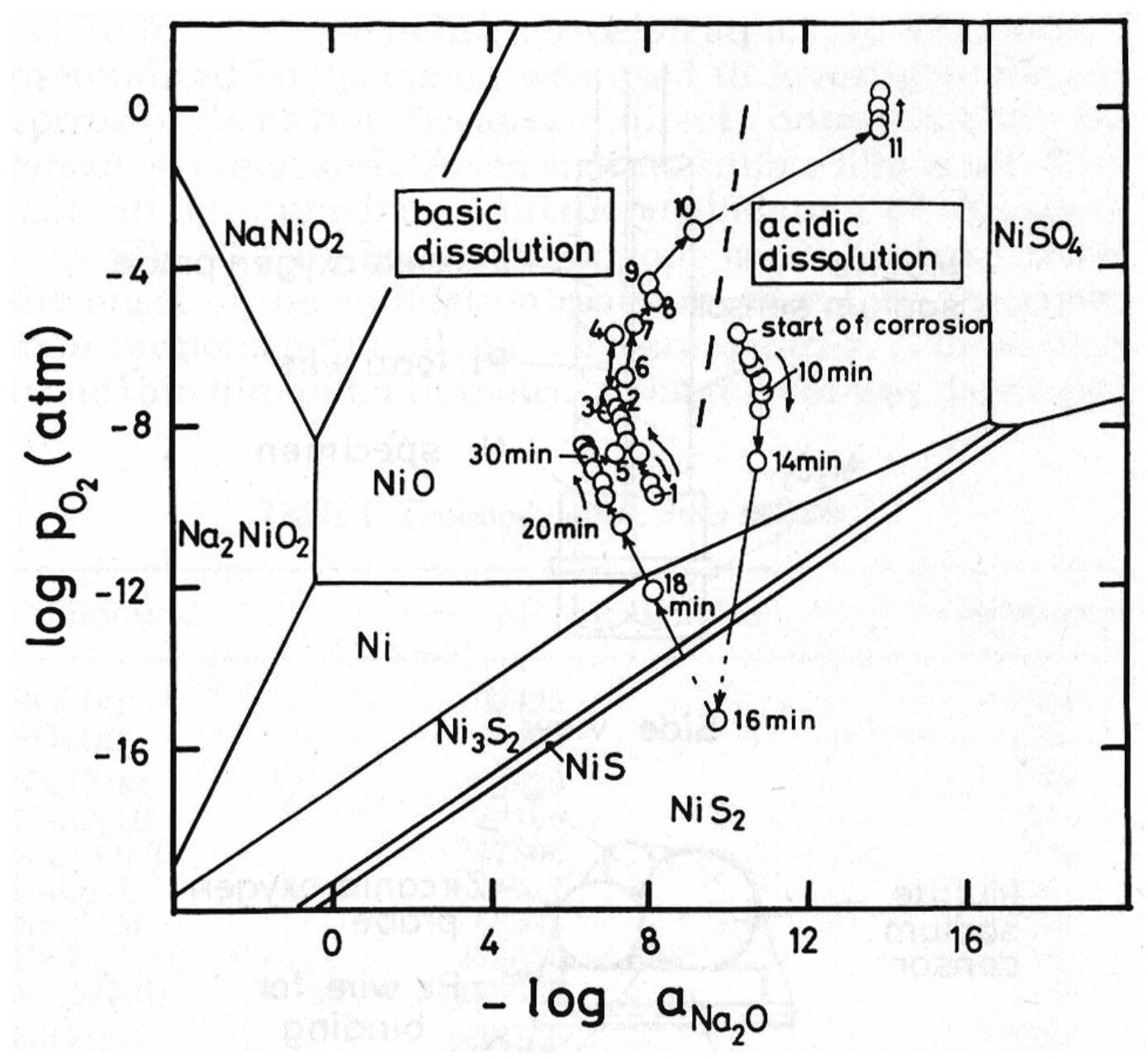

Figure 9. Trace of basicity and oxygen activity measured for a preoxidized $99 \%$ $\mathrm{Ni}$ covered with a $\mathrm{Na}_{2} \mathrm{SO}_{4}$ film at $900^{\circ} \mathrm{C}$ in $0.1 \% \mathrm{SO}_{2}-\mathrm{O}_{2}$ gas atmosphere (preoxidized at $900^{\circ} \mathrm{C}$ for $4 \mathrm{~h}$ in $\mathrm{O}_{2}$ ). Numbers in the figure designate the reaction time in hours except as indicated. Severe sulfidation and corrosion resulted. Coupon thickness: $2 \mathrm{~mm}$ (7). 
The various electrochemical experiments (cyclic voltammetry, chronopotentiometry, and dynamic polarization measurements) by Shi and Rapp provide further insight into the role of $\mathrm{Cr}$ in abating hot corrosion (15). Upon the cathodic polarization of $\mathrm{Na}_{2} \mathrm{SO}_{4}-\mathrm{Na}_{2} \mathrm{CrO}_{4}$ solutions at $1200 \mathrm{~K}$, despite the thermodynamic stability of chromite ions under reducing conditions, the direct conversion of chromate to chromite was not observed. Rather, an electrochemical intermediate species was formed which upon further reduction, led to a precipitation of solid $\mathrm{NaCrO}_{2}$ or $\mathrm{Cr}_{2} \mathrm{O}_{3}$ in basic and neutral solutions, respectively. These observations support an earlier suggestion by the authors that chromate ions during hot corrosion can precipitate back onto reduced local sites on a corroding substrate to seal the alloy and provide protection, as illustrated in Fig. 10 (14).

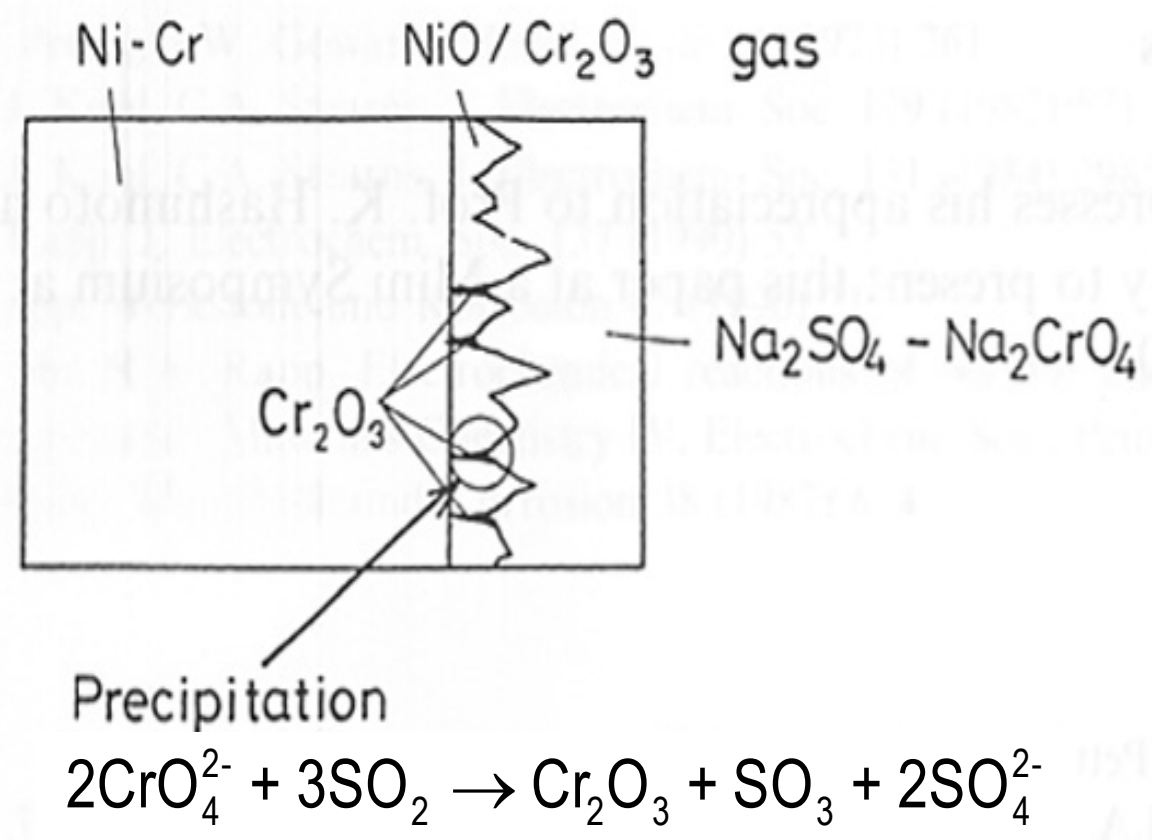

Figure 10. One action of chromium in inhibiting the hot corrosion attack at scale grain boundaries and other defects (14).

\section{Mechanism of Chromium Protection in Hot Corrosion}

The favorable influence of $\mathrm{Cr}$ as an alloying addition to alloys of $\mathrm{Ni}$-, $\mathrm{Fe}$ - or $\mathrm{Co}-$ base in abating Type I hot corrosion results from two complementary actions: 1 . As a buffer (upon forming chromite or chromate ions) to restrict an increase in melt basicity as the oxides of $\mathrm{Ni}, \mathrm{Fe}$, or Co form acidic solutes, and 2. Upon the backward precipitation of solids blocking the reducing sites at the scale/alloy interface.

In support of the first action: according to the chromia solubility results of Figs. 1-4, chromium solutes do not exhibit a "negative solubility gradient" in the salt film and are themselves not subject to the dissolution/reprecipitation illustrated in Fig. 6. In a reaction with the oxide ions released upon the acidic dissolution of the oxides of $\mathrm{Ni}, \mathrm{Fe}$ and $\mathrm{Co}$, the formation of chromite or chromate ions buffers the solution and prevents the 
basic dissolution of these oxides, whose basic solutes satisfy Case A of Fig. 7 leading to the dissolution/reprecipitation shown in Fig. 6. Likewise, the acidic dissolution of the oxides of $\mathrm{Ni}, \mathrm{Fe}$, or Co does not satisfy the negative solubility gradient criterion, and therefore does not support sustained hot corrosion.

Relative to the second favorable action of $\mathrm{Cr}$ as an alloying element, illustrated in Fig. 10, the failure of chromate ions to reversibly convert to chromite ions upon reduction, as shown in ref. 15, means that significant chromate solubility exists even near the scale/salt interface. Such chromate ions are reduced locally (in preference to sulfate ions) to deposit solids $\left(\mathrm{NaCrO}_{2}\right.$ or $\left.\mathrm{Cr}_{2} \mathrm{O}_{3}\right)$ which block reducing sites (scale grain boundaries and flaws) at the salt/metal interface.

\section{Acknowledgements}

The research reported here was sponsored by the National Science Foundation under Grant DMR 8620311.

\section{References}

1. R. A. Rapp, “Corrosion by Molten Salts”, Ch. in ASMI Handbook, 13, p. 117.

2. R. A. Rapp and Y. S. Zhang, J. Metals, Dec., 47, (1994).

3. J. Stringer, Ann. Rev. Mater. Sci., 7, 477, (1977).

4. R. A. Rapp, Mater. Sci. Eng., 87, 319, (1987).

5. R. A. Rapp, Corrosion, 42, 568 (1986).

6. C. O. Park and R. A. Rapp, J. Electrochem. Soc., 133, 1636, (1986).

7. N. Otsuka and R. A. Rapp, J. Electrochem. Soc., 137, 46, (1990).

8. Y. S. Zhang, J. Electrochem. Soc., 133, 655, (1986).

9. Y.S. Hwang and R. A. Rapp, J. Electrochem. Soc., 137, 1276, (1990).

10. R. A. Rapp, Metall. Mater. Trans., 31A, 2105, (2000).

11. J. A. Goebel and F. S. Petit, Meta, Trans., 1, 1943, (1943).

12. R. A. Rapp and K. S. Goto, "Hot Corrosion of Metals by Molten Salts", in Molten Salts 1, eds. J. Braunstein and R. Selman, Electrochem. Soc., 159, (1981).

13. C. O. Park and R. A. Rapp, J. Electrochem. Soc., 133, 1636, (1986).

14. N. Otsuka and R. A. Rapp, J. Electrochem. Soc., 137, 53, (1990).

15. D. Z. Shi and R. A. Rapp, Werkstoffe und Korrosion, 41, 215, (1990). 